Revista Iberoamericana. Vol. LXVII, Núms. 194-195, Enero-Junio 2001, 15-29

\title{
EL PÚBLICO FEMENINO DEL MODERNISMO: DE LA LECTORA FIGURADA A LA LECTORA HISTÓRICA EN LAS PROSAS DE GUTIÉRREZ NÁJERA
}

\author{
POR \\ José María Martínez \\ The University of Texas-Pan American
}

Es obvio que la recepción del Modernismo entre el público femenino de su tiempo es uno de los vacíos más graves en la tarea de reconstrucción de este movimiento. Puede decirse, resumiendo, que hasta el presente la recepción de sus textos se ha visto sobre todo en sus dimensiones generales y teóricas (Marini-Palmieri), político-sociales (Mainer, Aching), estrictamente literarias (Zuleta), o metacríticas (Blasco, Celma). Sin embargo, tanto en esos trabajos como en otros centrados en autores particulares (Oviedo 364; Jrade 24; Darío, Poesía xxxix), las referencias a esa audiencia femenina no dejan de ser esporádicas y superficiales, y en absoluto guardan proporción con hechos tan relevantes como la elección de ese público como audiencia ideal para la primera edición de Azul..., la conocida popularidad de muchos modernistas en esos círculos sociales, la existencia de proyectos editoriales como Elegancias o la inclusión de secciones como “Azul pálido” en la Revista Azul de Gutiérrez Nájera. Como deja demostrado uno de los más recientes “estados de la cuestión modernista”(Cardwell) conviene recuperar la historia del movimiento, para así evitar las reinvenciones y mistificaciones a que éste se ha visto sujeto con tanta frecuencia; y privarle de su audiencia femenina es, evidentemente, privarle de uno de sus componentes más característicos.

La reconstrucción de ese panorama es una empresa llena de dificultades pues, como ocurre con otros intentos semejantes (Krueger), dicha tarea ha de apoyarse sobre todo en testimonios indirectos, ya que por circunstancias históricas por todos conocidas, los escritos femeninos finiseculares acerca de la producción modernista son escasos y, en general, se reducen a comentarios de lectoras especializadas, como es el caso de Delmira Agustini o Gabriela Mistral (Oliver Belmás 137-63). Pero, a la vez, esta reconstrucción resulta sumamente necesaria, ya que uno de los hechos más sobresalientes en este sentido es el amplio número de variantes de lector femenino existentes en los textos modernistas, una recurrencia que justifica incluso la postulación de la mujer lectora como otro de los tipos consagrados de mujer finisecular, junto a la “mujer ángel” y a la femme fatale. Esa gama de variantes comprendería tanto la lectora histórica-extratextual, bien sea conocida (la Delmira Agustini que lee a Darío; Oliver Belmás 137-54) o anónima (la señorita L.F.G.R., que espera ansiosa la segunda edición de Azul..; Darío, Azul 32), como la lectora-personaje (la Alda de El donador de almas; Nervo 216). Entre ambos polos quedarían incluidos a su vez modelos como la destinataria del texto (la Marquesa de Peralta a quien va dedicado 
“Blasón”; Darío, Poesía 188), la narrataria extradiegética (la Julia para quien, entre otros, se relata "El escuerzo"; Lugones 151) o la narrataria intradiegética (la Helena de De sobremesa, Silva 350). Considerando además que entre esas variantes existe una densa red de interferencias mutuas, y que esta presencia femenina se explica también desde la progresiva participación de la mujer occidental en la vida pública y desde el acceso de ésta a los bienes culturales, el Modernismo podría suponer, a la vista de la posterior historia literaria, la ya definitiva entrada del público femenino en el desarrollo de las literaturas que el tiempo ha acabado convirtiendo en canónicas.

La perspectiva elegida en este trabajo es la del análisis de la lectora-personaje en la prosa finisecular y, concretamente, en la prosa ficcional de Manuel Gutiérrez Nájera, un autor con rezagos románticos pero considerado ya de forma unánime como integrante del canon modernista. Es cierto, o por lo menos no recuerdo, que salvo el cuento de Amado Nervo "Una historia vulgar" (Nervo 142-45), no existe en la producción modernista ninguna narración vertebrada exclusivamente en torno a un personaje de este tipo. Pero también es cierto que su aparición en las prosas najerianas es tan recurrente que su análisis no puede sino ayudar a entender mejor a las lectoras históricas de los textos del mexicano y, por extensión, de los demás modernistas. No en vano, la lectora histórica suele estar siempre cercana a la lectora pretendida por el escritor y ésta, a su vez, no deja de ser un ente de ficción, como lo es también la lectora-personaje. ${ }^{1}$ En otro lugar he tratado de explicar por qué Gutiérrez Nájera puede ser un escritor modelo para estudiar este problema (Martínez, 233-241). Resumiendo ahora esas razones, hay que decir que en su bibliografía abundan los datos que hablan de su popularidad en los círculos femeninos, de la profusión de textos suyos explícitamente dirigidos a esa audiencia concreta, de sus repetidas contribuciones en revistas femeninas y de su también frecuente lectura de literatura escrita por y para mujeres. Por otro lado, el conjunto de su producción demuestra cómo la compartimentación tradicional que se ha hecho de los periodos literarios es especialmente perturbadora en el nivel de la recepción textual, ya que a pesar de que esa producción suya contiene tanto elementos románticos como modernistas, esto en ningún momento parece responder a la existencia de dos públicos femeninos diferentes. En otras palabras, si cabe aceptar — con matices - cierta evolución o convivencia estilística en el nivel de la producción najeriana (Gutiérrez, "Manuel Gutiérrez Nájera”) no es posible hacer lo mismo con el nivel de su recepción, que no habría sufrido cambios esenciales a lo largo de su diacronía, y por ello las lectoras najerianas supondrían un vínculo de continuidad entre sus textos románticos y sus

\footnotetext{
${ }^{1}$ El mismo Gutiérrez Nájera parece confirmar la proximidad de estos tres ámbitos cuando asegura que el público es, para él, “un ser perfectamente fantástico; un maniquí que nosotros mismos componemos y cuya naturaleza cambia y se trasforma, como el termómetro, como el corazón de una coqueta. Hechura nuestra, posee nuestras propias debilidades y nuestras mismísimas flaquezas" (Cuentos completos 288). La terminología de los diferentes tipos de lectora me parece clara y también suficientemente extendida entre la crítica, por lo que renuncio a ulteriores explicaciones. Advierto simplemente que en el presente trabajo los conceptos de "lectora figurada" y "lectora-personaje" se van a entender siempre como perfectos sinónimos. Por otro lado, las referencias parentéticas del texto cuyas fechas o páginas no vayan antecedidas por ningún nombre, remiten siempre a las obras de Nájera recogidas en la bibliografía final.
} 
textos modernistas. Sin embargo, aún más determinante que este hecho, lo es la condición de escritor-periodista de Nájera, que en él resultó el principal y casi único medio de vida y que le mantuvo inmerso en una actividad periodística realmente intensa y con una frecuencia que podría considerarse diaria. Todos sus textos en prosa, sin excepción conocida, tuvieron su primera aparición en publicaciones regulares, muy principalmente en periódicos y revistas de la capital mexicana. Evidentemente, ya que el componente pragmático del texto suele resultar más activo en el género periodístico que en otros géneros, la relación de ese texto con el ámbito del lector es también más frecuente e intensa, y por ello la presencia en los escritos najerianos de las diferentes variantes de lectora mencionadas arriba ha de esperarse - como de hecho sucede - densa y recurrente y, así, las fronteras entre la lectora histórica, la lectora pretendida y la lectora-personaje o figurada acabarán también por resultar especialmente permeables. Finalmente quedaría por recordar que esas lectoraspersonaje najerianas no son figuras aisladas en la escenografía modernista, y que podrían colocarse también al lado de la madre de las protagonistas de "La misa de seis", que aparece leyendo "un voluminoso tomo de novelas cerca de un elegante velador de metal dorado con cubierta de mármol” (Nervo 91); de la Lucía Jerez en cuya casa se conserva una lujosa biblioteca con obras de Allan Poe y Alfredo de Musset (Martí 126-27), y de la Olga y de la Julia de De sobremesa que leen a Nietzsche y D’Annunzio y que Silva opone a Consuelo, “mi perezosa y sentimental amiga, que no ha leído, a Dios gracias, ningún libro que le haya quitado el perfume de la sencillez que la hace adorable” (Silva 344, cursivas mías). La lista podría aumentarse con la Aspasia de Dyonisos, de Pedro César Dominici, propietaria de un lujoso ejemplar de la Antígona de Sófocles (Meyer-Minnemam 281), y con la Susette dariana de "La muerte de la emperatriz de China”, cuyos libros “desflorados por su espátula de marfil, estaban en el pequeño estante negro, con sus hojas cerradas, sufriendo la nostalgia de las blandas manos de rosa, y del tibio regazo perfumado” (Darío, Azul 243).

A la hora de interpretar la construcción najeriana de la lectora-personaje y de identificar sus conexiones con la lectora histórica y la lectora pretendida, lo primero que hay que notar es que aquélla aparece en todos los formatos a los que dio lugar la prosa ficcional o semificcional del mexicano (cuentos, crónicas, fragmentos novelescos, etc.), los cuales a su vez tienen como característica común una brevedad que, junto a la agitada actividad periodística del autor, justifican la ausencia de una elaboración profunda y suficientemente individualizada de esos personajes. Este hecho, sin embargo, tiene la ventaja de presentar a esa lectora-personaje como algo estereotipado, es decir, de mostrar sus rasgos sobresalientes de forma inmediata y, por tanto, de hacer de ella una referencia útil para las lectoras figuradas de los demás modernistas. Al mismo tiempo, como contrapartida a esa supuesta superficialidad y como prueba también de la importancia que para Nájera tenía la condición lectora de sus personajes femeninos, son numerosas las ocasiones en las que el autor les asigna la lectura como actividad antonomástica, como si ésta fuera uno de sus primeros rasgos definidores. Así, en “Berta y Manon”, una de las protagonistas “tiene veinte años, y quisiera leer la vida, como quería de niña hojear los tomos de grabados que su padre guardaba” (Cuentos completos 168), y de una de las mujeres de "La mancha de Lady Macbeth” se recuerda “con cuánta ansia esperaba antes en la noche la hora en que estuvieran todos ya dormidos, para encender la vela y leer un libro" (392). Por otro lado, y como interesante contrapunto, debe recordarse que en las prosas najerianas los lectores-personaje de género masculino son 
prácticamente inexistentes, y, por ello, el análisis de la lectora figurada podría también sentar las bases para el estudio de lo que cabría llamar una poética modernista específicamente femenina.

En cuanto a la descripción de la lectora-personaje ésta, en general, corresponde casi siempre al tipo idealizado de la mujer angelical, que a veces recuerda a la mujer prerrafaelita o también a las mujeres de los cuadros de la escuela flamenca o de los de Rubens, referencias éstas que no parecen ajenas a los conocimientos pictóricos del mexicano (Obras. Prosa 290-91). Así la Luz de "El diputado”, es “rubia”, está "triste”, lee la carta de su novio con "delgada vocecita", tiene unas "mejillas de camelia”, y en un momento de la narración "desabotona el cuello de su vestido, y por el hueco abierto deja ver su garganta, blanca y torneada. Entonces pone un brazo sobre la mesa y en el brazo reclina con indolencia la cabeza" (Cuentos completos 339-47). Igualmente, la muchacha de una de sus crónicas teatrales, era una “jovencita de quince años, de ojos azules y rubia comme les blés,” que aún se encontraba “deletreando la vida,” que acaba de "soltar la mano del padre Ripalda” y a la que dan deseos, “al mirarla, de prestarle la María de Jorge Isaacs” (Obras VI 146). Por su lado, la mujer fatal aparece como lectora en un número de ocasiones bastante inferior. Una de esas mujeres fatales es 'Mme. Theo', cuyos ojos "ebrios de malicia, buscan libros prohibidos que leer” (Obras VI 418); otra es la protagonista de las “Aventuras de Manon”, una artista y lectora voraz de los periódicos y crónicas que relatan sus aventuras en la ciudad de México (Mañana 85-103). Teniendo en cuenta la diferencia numérica entre estos dos grupos de lectoras-personaje y recordando que Nájera comparte el tradicional entendimiento de la oposición entre ambos tipos (Mañana 68-69), hay que pensar que su asociación entre el acto de lectura y el tipo de lectora-personaje — en este caso la mujer angelical— estará lleno de significado y que, por tanto, su concepción de la lectura femenina ha de entenderse asociada a esa concreta caracterización de la mujer. Por ello, notas como pasividad, sentimentalismo, melancolía, esteticismo o capacidad evocadora van a ser los que con más frecuencia aparezcan acompañando a los actos de lectura de las lectoras figuradas najerianas. Lo que por otro lado conviene también recordar, es que ese concreto paradigma femenino tiene una ascendencia nórdica o europea y no corresponde al grupo racial dominante en México sino al que la cultura de ese país y el propio Nájera asociaron siempre a sus élites económicas y sociales (Hale 360-61, Gutiérrez Nájera, Cuentos completos 323). No es casual, por ello, que las lectoras-personaje najerianas compartan explícitamente esa procedencia extranjera, y así la rubia Catherine de "Una fiesta en Chapultepec" viva en Londres (Obras. Prosa 249) y la Magda de Por donde se sube al cielo sea una "voluble parisiense" (13). Por ello puede decirse que a través de esta concreta configuración de sus personajes, Nájera habría buscado facilitar la identificación entre sus lectoras pretendidas e históricas y estas lectoras figuradas situadas en la cima de la pirámide socioeconómica del país, participando así de las estrategias ideológicas y estilísticas que habrían propiciado su entrada, y la de los demás modernistas, en la dinámica económica y cultural de las clases privilegiadas (Aching passim). Esta ubicación social de las lectoras-personaje se confirma también con las costumbres o actividades que Nájera les asigna en sus narraciones y también con la reacción que despiertan en los coprotagonistas de la historia. Las compañeras de colegio de Magda se preguntan si ésta es “riquísima”, ya que tenía “una plegadera de marfil y unos anteojos de teatro. ¿Leería novelas? ¿Iría al teatro? [...] Cierto amigo de su mamá la 
había obsequiado con dos libros, que, a hurtadillas, leerían en el jardín. Y las alumnas, oyendo aquel relato interminable, la miraban con muestras de respetuosa admiración” (Por donde 16-17). Por su lado, Paz, de "La mancha de lady Macbeth", que de joven solía hojear "el último número de La Moda”, se encuentra ahora ansiosa por "lucir mis trajes y mis alhajas en la ópera", tiene en su casa "una escalera lujosa por la que se sube al comedor de mármol, lleno de azaleas y camelias”, y, ya casada, se dedica a obras de caridad, a esos "pobres de tu Conferencia, las viudas y huérfanos a quien tú socorres” (Cuentos completos 385-86). Este último tipo de actividades eran también frecuentes entre las mujeres de los grupos acomodados del porfiriato, de los que formaban parte, entre otras, las directoras y colaboradoras de algunas revistas femeninas que contaron con la repetida colaboración de Nájera (cfr. Mapes 159-204; Contreras 32 y Pasternac 151).

Igualmente, resulta llamativa la frecuencia con que los actos de lectura femenina se ubican en unas condiciones espacio-temporales que también pueden considerarse recurrentes y que en el nivel simbólico vinculan esos momentos a paradigmas como la intimidad, el recogimiento personal o la actitud contemplativa. La ubicación temporal de las lecturas ficcionales najerianas suele darse en los atardeceres o en los momentos nocturnos de la jornada, como ocurre en el caso de la Memé de "La venganza de Mylord”, a la que Nájera imagina leyendo cartas y periódicos en la quietud de su casa, cuando "la tarde se recoge y comienzan a asomarse las estrellas" (Obras. Prosa 11), y la Enriqueta de "La mancha de lady Macbeth”, que lee la carta de su amiga cuando "la noche había cerrado casi por completo. Sólo brillaban dispersos rayos de luz pálida” (Cuentos completos 386). En el contexto de la sociedad burguesa y moderna —el que tienen las prosas de Nájera- puede decirse que el resultado final de estas presentaciones del acto de lectura es la ubicación del mismo en los momentos de la jornada más ajenos a las actividades lucrativas, siendo fácil, por tanto, asociar esa lectura al ámbito de lo espiritual, del ocio y de la contemplación, de considerarlo como una actividad ajena a los valores utilitarios más inmediatos. De esta forma, la lectora-personaje reproduce igualmente la condición de elemento ornamental o de "sujeto de hornacina” que para la mentalidad burguesa tenía la mujer histórica del pasado fin de siglo, condición de la que los propios modernistas se hicieron eco en sus escritos no ficcionales (Darío, Obras desconocidas 112, y Darío, Poesía xxxviii). Por su parte, la ubicación espacial de los actos de lectura se concentra principalmente en espacios interiores (salas y alcobas) y, en mucha menor medida, en exteriores domesticados (parques y jardines), concretándose los primeros, casi siempre, en el típico interior preciosista de los textos finiseculares. Obviamente, esta atención a la interioridad corresponde al hecho histórico de la lectura en espacios privados —a la privacy de la que habla Flint (58) — y también a la ausencia efectiva de la mujer del espacio público, pero, sobre todo, hace que tanto el acto de lectura, su sujeto (la mujer) y su objeto (el libro o texto) se impregnen del contenido de compensación ilusionante que para el burgués poseen los objetos y fetiches alojados en este tipo de interiores (Benjamin 182). En este sentido, es decir, en cuanto esos interiores ficcionales se corresponden con el interior doméstico de las clases acomodadas del xix, las lectoras figuradas de Nájera son, también, lectoras históricas. Así, de la misma manera que el hombre privado "realista en la oficina, exige del interior que le mantenga en sus ilusiones” (Benjamin 182), la Memé de "La venganza de Mylord” descansa y lee en la "quietud alegre" de su casa, mientras en la ciudad piensan en "construir ferrocarriles y en 
tender una red de alambres telefónicos en el dominio de las lechuzas y los gatos” (Obras. Prosa 11). En concreto, los espacios de lectura más recurridos por Nájera son la sala de la casa, la ventana, la alcoba individual y el lecho. En este contexto, pues, Nájera presenta el acto de lectura como dependiente de los espacios de la identidad e intimidad personales la casa, la alcoba, el lecho- (Bachelard passim), pero también de aquel otro - la ventanaigualmente frecuentado por el Modernismo para significar la dialéctica entre interioridad y exterioridad (Martínez 121-25). La recurrencia del “espacio ventana” tiene su importancia, ya que, como el hecho mismo de la lectura, se encontraría dentro de lo que podría llamarse “isotopía de lo visual”, haciendo así que intimidad y visualidad sean otras de las notas caracterizadoras de la lectura femenina najeriana. Sobre esta dimensión visual volveremos más adelante. En cuanto a la intimidad, aunque a veces Nájera alude a algunas lecturas colectivas o compartidas (Cuentos completos 386-87), la mayoría de sus lectoras-personaje son lectoras solitarias ubicadas en esos espacios individualizadores y que con sus lujosos y preciosistas decorados lo hacen a la vez burgués y esteticista. Podría recordarse ahora la sala, la alcoba y el lecho de Magda, que están amueblados y adornados con numerosos objetos y bibelots de cosmopolita procedencia (Por donde 11-14), o también la habitación de Paz, tan colmada de objetos que podría ser un ejemplo ideal para la propuesta de Angel Rama que asegura que ese abigarramiento fetichista representa el intento de autoposesión del sujeto burgués (La ciudad letrada 396; Darío, Poesía xxxvii). Pero más interesante resulta todavía la alcoba descrita por Nájera en la presentación de su "Biblioteca Honrada”, ya que dicho texto está dirigido a las lectoras pretendidas y se concreta en unos términos que, a la vista de la figuración de los espacios burgueses comentada antes, confirma una vez más la cercanía entre la lectora histórica y la lectora-personaje del mexicano. Nájera quiere que los volúmenes de su "Biblioteca Honrada” encuentren un lugar “en la caliente alcoba y junto al lecho, cuyo blanco lino invita al sueño [y donde] hay una mesa de papel mascado, sustentando la palmatoria de cristal, la tetera de porcelana y la cuchilla ebúrnea con que abre usted las páginas fragantes de La vida moderna o de La Moda [...] junto a los guantes que llevó usted a la tertulia, entre la transparente taza china y el ramito de flores agostadas" (Mañana 33). A la vista de todo lo anterior queda confirmado el carácter efectivo y consistente de esa recurrencia en la presentación najeriana de las relaciones espaciotemporales del acto de lectura, y por ello cabe pensar que éste sería perfectamente susceptible de recibir la caracterización de los famosos cronotopos baktianos. Cabría aceptar entonces la existencia de un cronotopo de la lectura femenina modernista y, consecuentemente, afirmar la condición tipológica del personaje que lo habita. La lectorapersonaje se convertiría así una figura más de la escenografía consagrada del Modernismo.

De forma similar a como la configuración de ese cronotopo vincula la lectorapersonaje najeriana con el nivel histórico, lo mismo ocurre con la asignación de diversos formatos de lectura a esas lectoras, formatos que en la prosa del mexicano son tan variados como los exigidos por la cultura de la moderna ciudad letrada a la que también se refiere Rama (71-104). La consolidación del capitalismo y la consecuente diversificación de la actividad publicitaria y escritural, explica que los textos leídos por las lectoras ficcionales de Nájera incluyan tanto novelas como poemarios, periódicos, revistas, devocionarios, formularios burocráticos, recibos comerciales, cartas personales, diccionarios, almanaques, 
etc. ${ }^{2}$ De las implicaciones de esta diversificación interesa ahora detenerse en dos aspectos. El primero de ellos es el juego de perspectivas implicado en la inserción de textos epistolares en los relatos de ficción, y el segundo la existencia de formatos marcados por la convivencia de signos grafemáticos y signos visuales. En primer lugar, cabría decir que la frecuente asociación najeriana del género epistolar y el lector femenino resulta lógica y esperable, ya que el mexicano, que fue lector de epistolarios escritos por o para mujeres (Obras VI 191 y Obras III 216-17), no hacía con ello sino cultivar lo que había sido una parcela de la literatura no canónica durante los siglos XVIII y XIX, acanonicidad que Flaubert había sintetizado al afirmar que este género era uno de "style exclusivement réservé aux femmes" (Planté 11). Las razones por las que ambos elementos — lectora y carta— quedan asociados en el momento histórico-literario de Nájera pertenecen a diferentes niveles y por ello pueden servir también para ampliar la caracterización de su lectora-personaje. Así, se han visto razones de tipo cultural, en cuanto que las cartas son textos no mediatizados por la paratextualidad y por tanto resultan apropiados para un público cuya perceptibilidad se considera principalmente intuitiva. También existen causas de tipo social, pues lo epistolar se convertiría en la vía de expresión de ámbitos y experiencias femeninos (el hogar, etc.), que no habrían sido recogidos en otro tipo de discursos. Habría igualmente razones de tipo literario, ya que lo espistolar habría sido un recurso frecuente en géneros de tradicional audiencia femenina (la novela de folletín, por ejemplo), y razones de tipo psicológico, puesto que se trataría de un discurso apropiado para la exposición inmediata de afectos y sentimientos; asimismo su intensa oralidad reduciría el distanciamiento entre lector y texto que existiría en géneros lingüísticamente más elaborados (cfr. Planté, passim, y Nies). Todas estas perspectivas intervienen en la configuración de la lectora-personaje najeriana, que por ello queda presentada como un sujeto marginal en el conjunto social, sentimental y emocionable, ajeno a lecturas eruditas o utilitarias e intensamente sugestionado por el contenido de este tipo de textos. Lo más importante para nuestro propósito es, sin embargo, el juego de perspectivas e identificaciones generado con la reproducción de esos textos epistolares. Es decir, en el momento en que esas cartas del nivel de la anécdota se reproducen literalmente, como ocurre en "La mancha de lady Macbeth" (Cuentos completos 380-98) o en "La venganza de Milady" (Por donde 417), éstas devienen accesibles, sin mediación ni divergencia alguna, al lector histórico y hacen que la lectora-personaje y la lectora histórica sean receptoras del mismo texto y por tanto se vean inmersas en un intenso proceso de identificación. Esa identificación es aún más profunda si se considera que también implica una coincidencia del tiempo de la lectura ficcional con el tiempo de la lectura real y que por consiguiente la lectora histórica acaba viviendo una existencia simultánea a la de la lectora-personaje e, incluso, condicionando la actividad lectora de ésta, ya que, en esa coincidencia de perspectivas, el progreso de la lectura ficcional pasa a depender directamente del desarrollo de la lectura histórica. Por otro lado, la reproducción de un texto homodiegético

\footnotetext{
2. Así, las mujeres de Nájera aparecen leyendo cartas (Obras. Prosa 11), periódicos nacionales y extranjeros (Obras. Prosa 11 y Cuentos completos 387), libros de poesía (339-41), crónicas (Mañana 101), almanaques (Cuentos completos 38; 312), noticias legales (Obras. Prosa II 409), devocionarios y libros piadosos (Cuentos completos 304; Cuentos crónicas 77), diccionarios (Obras. Prosa 221), novelas (Por donde 57; Cuentos completos 264). Los formatos de aparición más frecuente son las cartas y las novelas.
} 
como la carta priva a éste de su carácter tradicionalmente privado y lo coloca en la esfera de lo público, facilitando así la multiplicación de una única lectora-personaje en la variedad indeterminada de las lectoras históricas y, por tanto, facilitando la identificación de estas lectoras históricas entre sí.

Estas interesantes combinaciones de perspectivas e identificaciones entre las diferentes lectoras no se reducen a los casos de textos epistolares. Otra situación semejante es la producida con la interpelación repentina, a mitad de texto, a una narrataria anónima, como ocurre en "La venganza de Milady" (Cuentos completos 416). Esa interpelación in medias res es especialmente efectiva porque, al no darse al comienzo de la narración, la lectora histórica no ha contado inicialmente con la oportunidad de separar su identidad de una receptora distinta a ella y, por tanto, esa llamada rompe bruscamente su pasividad en el desarrollo de la anécdota y facilita su ingreso en el nivel textual. Se produce, pues, una quiebra de identidad original de la lectora histórica, quiebra que resulta en la ubicación de esa lectora en dos niveles distintos — el textual y el extratextual—y que no sirve sino para intensificar la carga catártica propia del texto, es decir, para una más activa participación de la lectora histórica en la progresión de la anécdota que de este modo consigue reducir la distancia entre los dos tipos de lectora. Otra estrategia más es la reflexión de las lectoraspersonaje acerca de las mujeres de un segundo nivel ficcional, es decir, acerca de los personajes de sus respectivas lecturas. Ocurre, por ejemplo, cuando Eugenia queda fascinada al contemplar a Magda y repasa "con la imaginación todos los grandes nombres que había leído en los periódicos de modas: ¿sería la princesa H?, ¿la duquesa de Z?” (Por donde 31); en "La mancha de lady Macbeth”, Paz recuerda a Enriqueta que la madre de ésta le "parecía una de esas reinas, una de esas grandes damas cuyos retratos vienen en $L a$ Ilustración. La edad no alteró nunca sus facciones: era, como le dijo algún revistero de salones, 'la más bella caída de la tarde'” (Cuentos completos 387). Otro caso especialmente interesante es el de la protagonista de las “Aventuras de Manon”, la cual elabora o confirma su propia identidad a partir de una lectura de los textos de ese segundo nivel ficcional en los que ella aparece como personaje. Manon cree ser lo que lee de ella misma: "Vamos — decía en voz alta — ¿ ¿soy hermosa? Los cronistas lo han dicho muchas veces [...]: ¡Soy la reina! Los hoyuelos de mis brazos mórbidos se ríen de los otros brazos [...] Mi garganta es de mármol, y las pulidas redondeces de mis hombros causan envidia a las estatuas griegas [...] Sí; yo leí todo eso muchas veces en revistas y crónicas de bailes; [...]¡Soy hermosa, divinamente hermosa!’(Mañana 101; énfasis mío). Creo que es obvio que lo que Nájera está exponiendo en estos casos es su entendimiento del proceso receptivo de sus lectoras pretendidas, es decir de la propensión de éstas hacia la identificación con los personajes femeninos ficcionales alojados en ámbitos sociales y culturales de índole elitista, una identificación que, como ya se vio, también existía en el caso de las lectoras históricas. Así, para las lectoras figuradas, esos modelos leídos se acaban convirtiendo en modelos vitales y por ello, al ser leídos por la lectora histórica, estos textos terminan por adquirir un carácter especular.

Por lo que se refiere a la convivencia de componentes textuales y figurativos en el mismo formato, esto interesa porque entre ambos tipos de componentes se genera una intertextualidad que concluye en una emergencia de la isotopía de lo visual, así como en una significativa serie de equivalencias metafóricas entre los objetos y los sujetos de la lectura 
femenina. Como se recordaba arriba, las lectoras-personaje najerianas son lectoras de libros y cartas, es decir, de textos grafemáticos, pero igualmente lo son de almanaques, revistas ilustradas, devocionarios y periódicos, o sea, de textos en los que ese componente grafemático coexiste con el figurativo. Enriqueta y Paz, en "La mancha de Lady Macbeth”, leen juntas la revista La Moda: "tú veías los figurines, yo leía las novelas; los patrones y las estampas de colores eran para ti; para mi el texto, cuando ya no te servía” (Cuentos completos 387). Lo mismo les ocurría a las lectoras históricas de El Álbum de la Mujer en el que colaboró Nájera, ya que ésta era una "revista de carácter literario que además [...] presentaba bellísimas litografías de hombres y mujeres célebres, cuadros y estampas mexicanos” (Contreras 32). En ese tipo de formatos, y sobre todo en los del ámbito periodístico, donde las estrategias por capturar al lector son especialmente numerosas y diversificadas (Sorensen), puede proponerse la existencia de cierta “rivalidad” entre ambos tipos de componentes, una rivalidad que llevaría al escritor a tratar de aproximar su texto a los parámetros receptores de un público acostumbrado a alternar mirada y lectura en el proceso de asimilación del contenido global de esas publicaciones. En este sentido, el recurrente sincretismo artístico y sensorial del Modernismo no debería verse sólo a partir del intenso esteticismo personal de los escritores sino también como producto de esa convivencia diaria y en el mismo espacio de dos distintos procesos decodificadores. Como cabría esperar, en las prosas najerianas esa inestable coexistencia de códigos va a decantarse por una emergencia de lo visual, ya que esta sensorialidad conviene mejor que la simple textualidad a una lectora-personaje también sensorial, concebida bajo los parámetros generales de la mujer figurada del Modernismo. Este incremento de lo visual se concreta principalmente en una intensa objetualización del formato leído por la lectora-personaje, el cual tiende a perder su identidad textual y a dejar pasar a un primer plano los elementos que lo cosifican o lo convierten en un "bibelot” más, en un objeto de lujo. Otros modernistas también registran este fenómeno, y así uno de los libros de la Lucía Jerez de Martí tiene una cubierta "de tafilete negro mate embutido con piedras preciosas: topacios" y ha costado a su comprador "las ganancias de un año” (Martí 127); por su lado, el diario que lee José Fernández en De sobremesa es un "grueso volumen con esquineras y cerraduras de oro opaco. Sobre el fondo de azul esmalte, incrustado en el marroquí negro de la pasta, había tres hojas verdes sobre las cuales revoloteaba una mariposilla con las alas forjadas de diminutos diamantes" (Silva 239). Igualmente, la protagonista najeriana de "Los matrimonios al uso" califica el misal que ha recibido como regalo de boda como “ $¡$ Una positiva alhaja! Los adornos son de acero [...] y en el centro de mis armas de relieve con la corona, el mirlo y la maquinita” (Cuentos completos 29; énfasis mío). Esa objetualización del libro implica una reducción de su identidad textual, que se puede concretar en la ausencia o reducción de elementos paratextuales, como ocurre con la "novela a la moda” de Magda, de la que no sabemos el título pero sí que tenía "sus páginas cerradas y su amarillo forro levantado por un cuchillo de nácar” (Por donde 14); en otras ocasiones esos libros se presentan como otros componentes más del ajuar femenino, sin especificaciones que los ubiquen en un nivel diferente a los demás objetos (Poesías completas I,130; Cuentos completos 396), o como productos de transacciones burguesas en los que las características físicas son tan o más importantes que los contenidos textuales (Cuentos completos 53). En definitiva, parece evidente que lo que trata Nájera es de homogeneizar semánticamente los componentes del 
acto de lectura, y así, a un lector femenino le debe corresponder un formato menos mediatizado por categorías textuales —intelectuales o abstractivas - y más un formato sensorial y paralelo por su preciosismo a la belleza idealizada de esas lectoras. En el mismo sentido debe entenderse que esa objetualización no afecte sólo al formato sino también a los contenidos de éste, que Nájera presenta repetidamente de forma inmediata, es decir sin recurrir a verba narrandi e incluso sustituyendo éstos por verbos de referencia visual. A la narrataria y también lectora-personaje de "La fiesta de Chapultepec" le comenta que sólo quiere "fijar en esta carta” el aspecto pintoresco y sensorial de la fiesta: "los árboles, llenos de globos multicolores, parecidos á pájaros de luz que se hubieran posado en cada rama; [...] los cabellos rubios, vistos a través de una copa de Champagne; labios rojos humedecidos por el Borgoña [...] y en lo espeso del arbolado, los focos eléctricos, como lunas viejas, como lunas que cayeron del cielo y se quedaron enredadas en las hebras de heno!” (Obras. Prosa 254). Después de toda esta objetualización del contenido, no es extraño que Nájera continúe: “Esto es, Miss Catherinne, lo que quiero hacer pasar a vuestros ojos” (254; énfasis mío). Por ello, la lectura femenina najeriana se puede entender también como mirada y las lectoras figuradas como personajes contemplativos. Así, la Miss Catherine para quien Nájera recreaba la fiesta de Chapultepec no es distinta de la Magda que, también lectora de cartas y novelas, pasaba "ratos larguísimos mirando el tapiz rosa de los muros y la varilla de oro que recorría la alcoba como un friso, las rosas encarnadas que salpicaban su soberbia alfombra, y los dibujos de la lámpara etrusca, que colgaba en medio de la pieza" (Por donde 14; énfasis mío). Y, finalmente, esto desemboca en la conversión de los ojos femeninos en los verdaderos protagonistas del acto de lectura, es decir, en una más completa sensorialización de ese acto, que puede llevar incluso a su conversión en un momento propio de la dialéctica amorosa entre la lectora-personaje y el autor del texto: "Estoy seguro de que usted, señorita, que ha fijado sus ojos circasianos en las primeras líneas de este artículo, lo dejo caer luego con desvío. Lo siento por las letras de imprenta, que si tuvieran alma, se helarían, como yo cuando no siento el calor y la luz de esa mirada” (Obras. Crítica 182; cfr. también Cuentos y cuaresmas 267).

De la misma forma que esa emergencia de lo sensorial en el acto de lectura resulta en una visualización del objeto (el libro), el sujeto de ese acto (la mujer) acaba igualmente afectada por ese proceso, es decir, visualizada, convertida a su vez en un objeto de lectura. Así, las mujeres figuradas de Nájera resultan transformadas metafóricamente en libros u otro tipo de textos, en formatos para ser leídos o contemplados por el lector, ahora un lector masculino. De la relevancia de esta concreta percepción nos dan testimonio claro los esquemas mentales de Nájera implícitos en el planteamiento que el mexicano se hace al hablar de las mujeres veracruzanas, cuando escribe que "si fuera lícito compararlas con los libros diría que están impresas en papel de lino” (Obras. Prosa 291; énfasis mío). Por ello, las mujeres najerianas van a aparecer con una variedad similar a la existente para los formatos de lectura. Así, la encantadora Silli "es un grueso infolio, pero un infolio empastado en pergamino, un infolio que yo leería con mucho gusto” (Obras VI 103) y Magda es “una mujer impresa en papel Whatman y con cantos de oro” (Por donde 31). La consecuencia más interesante de este hecho es la transfiguración del escritor en lector, es decir su parcial identificación con la mujer lectora, con quien ahora compartiría esa misma doble actividad decodificadora — lectiva y visual. En este sentido quizá el ejemplo más 
elocuente en ese proceso de identificación sea el que ocurre en "Las aventuras de Manon” (Mañana 85-103), donde el propio Nájera aparece convertido en narrador intradiegético que además tiene vocación de lector, como asegura la protagonista femenina al afirmar que éste "no viene a amarme sino a leerme" (90). Así, en cierto momento de la anécdota, ese narrador aparece leyendo y reproduciendo literalmente el diario de la protagonista (91-92), lo que, como se vio al comentar las lecturas epistolares, implica una clara identificación entre lector-figurado y lector-histórico, y, en lo que ahora interesa, entre el narrador (el Gutiérrez Nájera ficcional) y la lectora histórica. En consecuencia, lo que ocurriría en este caso particular sería la conversión del narrador en lector figurado de un tipo de textos de audiencia dominantemente femenina, es decir, una hipóstasis del autor y de un lectorpersonaje femenino y, por tanto, una especie culminación de ese proceso asimilatorio en el que Nájera ha considerado a la mujer como objeto de su lectura. La propuesta de esta hipóstasis entre Nájera y sus personajes no es algo aventurado, ya que se da también cuando Nájera utiliza las lectoras figuradas como vehículos de sus propias opiniones estéticas o morales (Cuentos y cuaresmas 259; Cuentos completos 129; Por donde 16) o cuando se anticipa y adivina las reacciones de la lectora-personaje ante la lectura de un texto (Cuentos completos 387; Obras. Prosa 249), lo cual, por su lado, no es sino la explicitación de la respuesta que Nájera espera o quiere de las lectoras pretendidas de esos textos.

Queda, por último, comentar los rasgos psicológicos que Nájera adjudica a la lectorapersonaje, y que, como se ha ido viendo, corresponden al estereotipo femenino de la mayor parte de los autores decimonónicos y finiseculares. En primer lugar, esas lectoras se presentan como personajes sentimentales o emotivos, lectoras sobre todo de novelas románticas, de cartas personales, de crónicas periodísticas y de otros formatos habitualmente ajenos a los discursos racionalistas o filosóficos. Del mismo modo, son lectoras a las que se ubica en situaciones de evidente intensidad emocional que muchas veces son ya momentos consagrados por la tradición literaria; entre esos momentos se encontrarían casos como la ausencia del amante ("El diputado"), las situaciones familiares conflictivas ("La mancha de lady Macbeth") o la proximidad del compromiso matrimonial ("Los matrimonios al uso”). Por ello, sus lecturas se convierten a veces en simples ejercicios sentimentales de ese personaje, sin repercusión argumental en el resto del relato, y concluyen con reacciones que son sobre todo inmediatas y marcadamente emocionales. Es lo que sucede en Por donde se sube al cielo, donde la lectura que hace Magda de las cartas de su infancia es un episodio sin peso real en el posterior desarrollo de la historia, pero donde ella lee esas cartas "una por una, sofocando risas y reprimiendo suspiros, [...] Sus ojos se iban entristeciendo conforme avanzaba la lectura; el arco de sus labios, primero dilatado por la risa, se cerró obstinadamente; se enjugó los ojos” (Por donde 13). La gestualidad perceptible en esta descripción asegura también que la sensualidad sea otro de los rasgos de esas lectoras figuradas, sensualidad que se corresponde con la visualización y objetualización que afectaba a los formatos textuales femeninos. Además de Magda, a quien le gustaba "sentir el roce discreto del lino y el hundimiento delicioso del colchón” (13-14) se encuentra el ejemplo de Miss Catherine, a quien la noticia de la fiesta de Chapultepec "le causará la misma impresión de frío que se experimenta al leer el primer capítulo del 'René’” (Obras. Prosa 249).

Otra de las notas claves de la lectora-personaje es su condición imaginativa o fantasiosa, es decir, su concepción como criatura capaz de recrear rápida e intuitivamente 
las propuestas o evocaciones ficcionales del autor. En este sentido, la imaginación es una fuerza activa que encamina a Nájera y a sus lectoras hacia el mismo punto de llegada. Por eso es especialmente frecuente en los momentos en los que aquél interpela o guía la lectura de sus narratarias y en aquellos en los que implícitamente queda descrita su lectora pretendida. En “Un matrimonio en París”, escribe:

[...] solamente la imaginación, esa loca de la casa, puede hacernos mirar las cosas lejanas, el lago de Como con sus villas perfumadas, las nieves del Monte Blanco y la grandiosa majestad del Vaticano. La imaginación es un caballo con alas como el de los dioses. Permita Ud. que doble la rodilla y que le ofrezca de ese modo un escalón seguro para que suba graciosamente al albardón. Deje Ud. flotar los pliegues de su traje de amazona y cubra sus delicados rizos de oro con el sombrero de copa, rodeado por una gasa azul. Aquí está el látigo y la rienda de listón color de rosa. ¡En marcha!

En dos minutos, hemos salvado el mar como las golondrinas. Nadie nos pide nuestros pasaportes ni registra nuestras maletas en Burdeos. Ya estamos en París. El corcel se hace invisible, el traje de amazona se convierte en un soberbio atavío de ceremonia, y clopinclopan entramos al templo de santo Tomás de Aquino. Allí se verifica el matrimonio de una amiga nuestra: Concha Miramón y Lombardo. (Cuentos completos 295)

Por su lado, las lectoras-personaje comparten esa misma caracterización y así, la hija del labriego rico que lee almanaques y alguna novela "que azuza su fantasía” es una “dormida soñadora” a quien la ciudad de México "se le figura mitad como sus amigas le han referido que es, y mitad como describe el novelista que ha leído las grandes capitales de Europa [...] Su imaginación abulta las diversiones de que va a gozar” (Cuentos completos 39). Por esta preeminencia de lo imaginativo, la lectura femenina no va a presentarse como un ejercicio intelectual, como la reconstrucción estructurada de un discurso previo, sino como una simple evasión a mundos ajenos (265), como una búsqueda de consuelo personal (387) o como ocasión también de un simple y desinteresado entretenimiento (358).

Finalmente hay que aludir a la inserción de esa lectora-personaje en dos de las principales coordenadas hermenéuticas de Nájera: la coordenada estética y la moralizante. En la primera podría incluirse realmente todo lo comentado hasta ahora, pues resulta obvio que a pesar de sus vínculos con la lectora histórica, la figuración de la lectora-personaje najeriana es producto de una idealización o de una muy particular selección operada por el autor sobre sus referentes históricos. Por su parte, la consideración moral del acto de lectura femenino no es frecuente en los escritos ficcionales del mexicano, aunque sí lo es en los de corte político, satírico o de crítica literaria. Un ejemplo de esa penetración de lo moral en lo estético podría ser el caso de la compañera de colegio de Magda, que guardaba en su cama “una novela cuyas primeras líneas no podría leer una mujer casada” (Por donde 16). De todas formas, lo más interesante es notar que esa carga moral siempre viene neutralizada por cierta dosis de frivolidad y galantería que el mexicano adopta como tono general en sus textos dirigidos a mujeres (Obras. Prosa II 282); es claro que esa elegante superficialidad resulta la perspectiva más apropiada para acercarse a una mujer lectora considerada a la vez como modelo de belleza y como ser habitante en los márgenes de la verdadera dinámica social. Es así como superficialidad y profundidad forman una oposición inoperante en estos escritos najerianos: “Hablemos ambos — propone Nájera a una de sus lectoras— de las cosas 
frívolas, esto es, de las cosas serias” (Cuentos y cuaresmas 76). Sin embargo, esta emergencia de lo frívolo o lo galante en sus textos femeninos, ese "mundo encantado" que se ha visto en las recreaciones de Nájera (Oviedo 253), parece llevar implícita una desconsideración del autor hacia su mundo referencial. Ya que la galantería, la frivolidad y la idealización son actitudes todas ellas que buscan el distanciamiento del sujeto de un mundo que se considera real e inevitable, esta literatura para mujeres acaba resultando para Nájera de menor importancia y trascendencia que la literatura centrada en su mundo más inmediato, es decir, en su mundo de periodista y crítico literario, en el mundo de la política o de la vida diaria de la sociedad mexicana o de la tradiciones culturales e intelectuales ya consagradas. Así queda de manifiesto en un párrafo que Nájera dirige a Emilia Pardo Bazán, un párrafo desmitificador pero por lo mismo particularmente informativo:

\begin{abstract}
Pero vamos a cuentas: a vd. le gustan tanto [los Goncourt], porque a las mujeres les halagan muchísimo los encajes, las plumas, las piedras preciosas, los cachivaches de porcelana [...] y en los Goncourt hay de todo eso [...] Sus libros son mosaicos preciosísimos, obtenidos a fuerza de incesante labor, y que recrean los ojos y el espíritu. Pero ¿no cree vd. que ese su arte es muy mucho artificioso? ¿no cree vd. que esos maestros mosaístas no son los maestros de la novelas contemporánea? ¿No atisba vd. algo de afeminamiento en el tocado y atavío de su estilo? ¿No le satisface más un buen Renán?

Le agradan tanto porque vd. es mujer y porque ellos son, bonitos, así como también le simpatiza Barbey d'Aurevilly, porque á las mujeres les gustan los hombres elegantes. Pero hay otros autores a quienes vd. conoce mejor que yo, y a quienes en el fondo- examínese bien—admira más. (Obras. Prosa II 264)
\end{abstract}

A pesar de la desmitificación operada sobre su propia literatura, esta cita de Nájera confirma que las lectoras del mexicano, ahora sin duda alguna sus lectoras históricas, son las razones conscientes de muchos de los componentes formales e imaginarios de sus prosas, así como de las de otros autores modernistas. La historia literaria se ha encargado por su lado de demostrar que esos componentes no fueron simplemente elementos marginales sino parte principal de la renovación estilística llevada a cabo por el Modernismo. Lo cual acaba por ratificar la propuesta inicial del presente trabajo, a saber, que la literatura modernista no habría sido la misma sin la participación de ese público femenino.

\title{
BiBLIOGRAFÍA
}

Aching, Gerard. The Politics of Spanish American Modernismo. By Exquisite Design. Cambridge: Cambridge University Press, 1997.

Bachelard, Gaston. La poética del espacio. México: Fondo de Cultura Económica, 1986. Benjamin, Walter. Iluminaciones II. Madrid: Taurus, 1972.

Blasco Pascual, Francisco Javier. "El estado de la cuestión: Modernismo y Modernidad”. Insula 485-487 (1987): 37.

Cardwell, Richard (ed.). ¿Qué es el Modernismo? Nueva encuesta, nuevas lecturas. Boulder: Society of Spanish and Spanish American Studies, 1993.

Celma Valero, María Pilar. La pluma ante el espejo. Salamanca: Universidad, 1989.

Contreras García, Irma. Indagaciones sobre Gutiérrez Nájera. México: Metáfora, 1957. 
Darío, Rubén. Obras desconocidas. Raúl Silva Castro, ed. Santiago: Prensas de la Universidad de Chile, 1934.

Poesía. Ernesto Mejía Sánchez, ed. con introducción de Ángel Rama y cronología de Julio Valle Castillo. Caracas: Ayacucho, 1985.

Azul... Cantos de vida y esperanza. José María Martínez, ed. Madrid: Cátedra, 1995.

Flint, Kate. "The Woman Reader and the Opiate Fiction”. The Nineteenth Century British Novel. Jeremy Hawthorn, ed. Londres: Edward Arnold, 1986. 47-62.

Gutiérrez, José Ismael. “Manuel Gutiérrez Nájera y su doble filiación literaria”. Revista de Filología de la Universidad de La Laguna 11 (1992): 103-114.

Gutiérrez Nájera, Manuel. Mañana de otro modo. Yolanda Bache Cortés, ed. et al. México: UNAM, 1995.

Por donde se sube al cielo. Belem Clark de Lara, ed. México: UNAM, 1994.

Cuentos, crónicas y ensayos. Alfredo Maillefert, ed. México: UNAM, 1992.

Cuentos y cuaresmas del duque Job. Francisco Monterde, ed. México: Porrúa, 1991. Obras VI. Crónicas y artículos sobre teatro, IV (1885-1889). Ana Elena Díaz Alejo y Elvira López Aparicio, eds. México: UNAM, 1985.

Cuentos completos y otras narraciones. Erwin K. Mapes, ed. Introducción de Francisco González Guerrero. México: Fondo de Cultura Económica, 1984. Obras IV. Crónicas y artículos sobre teatro. Yolanda Bache Cortés y Ana Elena Díaz Alejo, eds. México, UNAM, 1984.

Obras III. Crónicas y artículos sobre teatro (1876-1880). Alfonso Rangel Guerra, ed. México: UNAM, 1974.

Obras. Crítica Literaria (I) Ernesto Mejía Sánchez y Erwin K. Mapes, eds. Introducción de Porfirio Martínez Peñaloza. México: UNAM, 1959.

Poesías Completas. Pról. de Justo Sierra. 2 vol. Buenos Aires: Sopena, 1946.

Obras. Prosa. Introducción de Amado Nervo. Vol. II. México: Oficina Impresora del Timbre, 1903.

Obras. Prosa. Introducción de Luis G. Urbina. México: Oficina Impresora del Timbre, 1898.

Hale, Charles A. La transformación del liberalismo en México a fines del siglo XIX. México: Vuelta, 1991.

Jrade, Cathy L. “Modernist poetry”. The Cambridge History of Latin American Literature. The Twentieth Century. Vol. II. Roberto González Echevarría y Enrique PupoWalker, eds. Cambridge: Cambridge University Press, 1996. 7-68.

Krueger, Roberta L. Women Readers and the Ideology of Gender in Old French Verse Romance. Cambridge: Cambridge University Press, 1993.

Lugones, Leopoldo: Las fuerzas extrañas. Arturo García Ramos, ed. Madrid: Cátedra, 1996.

Mapes, Erwin K. “Manuel Gutiérrez Nájera: seudónimos y bibliografía periodística”. Revista Hispánica Moderna 19 (1953): 132-204.

Mainer, José Carlos. “1900-1910: nueva literatura, nuevos públicos”. Eutopías 3/1 (1987): 103-34.

Marini-Palmieri, Enrique. "Recepción del Modernismo literario hispanoamericano. ¿Sinceridad o afectación?” Acta Literaria 21 (1996): 25-43. 
Martí, José. Lucía Jerez. Carlos Javier Morales, ed. Madrid: Cátedra, 1994.

Martínez, José María. Los espacios poéticos de Rubén Darío. Nueva York: Peter Lang, 1995.

"El público femenino del Modernismo: las prosas de Manuel Gutiérrez Nájera”. Actas del XIII Congreso de la Asociación Internacional de Hispanistas. Florencio Sevilla y Carlos Alvar, eds. Madrid: Castilia, 2000. 233-241.

Meyer-Minnemam, Klaus. La novela hispanoamericana de fin de siglo. México: Fondo de Cultura Económica, 1979.

Nervo, Amado. Obras Completas. Vol. I. Madrid: Aguilar, 1962.

Nies, Fritz. “Un genre feminin?” Revue d'histoire litteraire de la France 78 (1978): 9941003.

Oliver Belmás, Antonio. Este otro Rubén Darío. Madrid: Aguilar, 1968.

Oviedo, José Miguel. Historia de la literatura hispanoamericana. Del Romanticismo al Modernismo. Madrid: Alianza Editorial, 1997.

Pasternac, Nora. "El periodismo femenino en el siglo XIX: Violetas del Anáhuac". Mujer y literatura mexicana y chicana. Culturas en contexto. Aralia López González, ed. et al. México: Colegio de México, 1990. 151-57.

Planté, Christine (ed.). L'epistolaire, un genre féminin? París: Honoré Champion, 1998.

Rama, Ángel. La ciudad letrada. Hannover: Ediciones del Norte, 1984.

Silva, José Asunción. Obra Completa. Héctor H. Orjuela, ed. Madrid: Archivos, 1990.

Sorensen, Diana. “Azul..., los contextos de lectura”. Hispamérica 40 (1985): 3-14.

Zuleta, Ignacio. La polémica modernista: El Modernismo de mar a mar. Bogotá: Instituto Caro y Cuervo, 1988. 